\title{
Peak Load Shifting Distribution of Multi-zone Fuzzy Group Decision-Making
}

\author{
Yang Li, Jia Liu, Liqun Gao, Zhi Kong \\ School of Information Science and Technology, Northeastern University \\ 3-11 Wen Hua Road, Shenyang 110004, China \\ E-mail: liyang@ise.neu.edu.cn
}

\begin{abstract}
On the basis of different expert knowledge structure, from the greatest factors in power limiting distribution, using the method combining Analytical Hierarchy Process (AHP) and fuzzy set theory, a fuzzy comprehensive group decision model for multi-objects and multi-zones power limiting distribution in peak load shifting is built up. The problem of power limiting distribution between multi-zones is researched. The result manifests this model is reasonable and applicable.
\end{abstract}

Keywords: AHP, Fuzzy set, Group decision, Power limiting distribution

\section{Current situation of foreign funds in China insurance industry}

With the quick development of economy, the power shortage circumstance is appeared in most eastern and central regions in our country. To alleviate the complexion of power shortage, national and regional electric capacities carry out large-scale invest item for extending generate electricity capacity (including SanXia item). But the increasing speed of power consumption is more larger than the one of extension of power basic equipments, the amount of power shortage in each region is large, although some economy and policy means were carried out to control peak load shifting, for the consideration of power grid safety, so power limiting control for some regions in electro-apex is essential. It is an urgent solving and having actual meaning problem that how to scientifically and rationally distribute limited power limiting capacity in each region and make the security of power grid of each region highest and loss least, according to power limiting criterion and safety requirement of each region, through the comprehensive analysis of benefit on society, economy and environment.

Peak load shifting distribution is an important task and it needs knowledge and experiment of many persons. At the same time, it is a little fuzzy. So the method of combining fuzzy sets theory with hierarchy analysis is used to discuss the multi-objective group decision of multi-zone peak load shifting, according to the systemic analysis of society, economy, resource and environment. Therefore, power limiting distribution belongs to nonlinear multi-objective group decision category.

\section{Construct Peak Load Shifting Distribution Decision System}

\subsection{Power limiting distribution guide line system and hierarchy structure building}

The reasonable time distribution of peak load shifting in multi-zone is for the sake of power capacity standard and least loss based on the grid security. In this aspect, there are many factors, which are related to range and time of power limiting, also the conditions of social economy, such as population, industry configuration, parameter of national economy and so on. Some of them can be showed in economic quantity. Such as population in power limiting area, number of electricity enterprises in power limiting area and gross product in power limiting area, etc. Furthermore, it is hard to estimate some potential indirect benefit like effect on economy, adjustment of economy structure, damage for environment. The necessity of peak load shifting control is usually appraised by economic benefit. And these always affect the distribution of power limiting time. So it has some deficiency. Thus, the guide line system and hierarchy structure (Fig 1.) should be established according to the parameters picking up from the factors affecting power supply limiting like society, economy and so on. This will be good to the reasonable distribution of power limiting time and least loss. And the law of clear conception, abundant information, easy calculation and show justice is necessary.

\subsection{Building and determining relative membership degree functions of each parameter}

Decision-making parameters always have four types in multi-objective decision problem. "a" is "excellent with large", "b" is "excellent with small", "c" is "fixed value" and " $d$ " is "inter-zone". 
The type of "fixed value" parameter is a kind of parameter that the excellent value is a constant. Inter-zone means that the parameter value in some fixed region is excellent. The purpose of decision parameter classification is for compare among same parameters.

According to the difference between decision parameter types, parameter set $\mathrm{F}$ can be classified.

$$
F=\bigcup_{i=1}^{4} F_{i}, \quad F_{i} \cap F_{j}=\Phi(i, j=1,2,3,4, i \neq j) .
$$

In this equation, $F_{i}(i=1,2,3,4)$ is the kind of $\mathrm{a}, \mathrm{b}, \mathrm{c}$ and $\mathrm{d}$ respectively, and $\Phi$ is null.

Because of the difference between multi-objective dimensions, it needs to standardize the decision matrix M. And then, the eigenvalue of each decision parameter in relative state can be got. The expression of standardization is as follows.

$$
\begin{aligned}
& a_{\max }=\max \left\{a_{i j}: 1 \leq i \leq n, 1 \leq j \leq r\right\} \\
& a_{\min }=\min \left\{a_{i j}: 1 \leq i \leq n, 1 \leq j \leq r\right\}
\end{aligned}
$$

( $r_{i j}$ is relative membership degree of parameter $j$ in zone $i$, max and $\min$ is the symbol for taking maximum and minimum respectively, $\alpha_{i j}$ is the objective value of parameter $j(r$ in all $)$ in zone $i(n$ in all $)$ and have character of fuzzy by effect of value and statistical error.)

For type a,

$$
r_{i j}=\frac{a_{i j}-a_{\min }}{a_{\max }-a_{\min }}\left(1 \leq i \leq n, 1 \leq j \leq r, f_{k} \in F_{1}\right)
$$

For type b,

$$
r_{i j}=\frac{a_{\max }-a_{i j}}{a_{\max }-a_{\min }}\left(1 \leq i \leq n, 1 \leq j \leq r, f_{k} \in F_{2}\right)
$$

For type c,

$$
r_{i j}=\left\{\begin{array}{ll}
1.0, & a_{i j}=a^{0} \\
1.0-\frac{\left|a_{i j}-a^{0}\right|}{\max \left\{a_{i j}-a^{0}\right\}}, & a_{i j} \neq a^{0}
\end{array} \quad\left(1 \leq i \leq n, 1 \leq j \leq r, f_{k} \in F_{3}\right)\right.
$$

$a^{0}$ is the optimal constant of parameter $f_{k}$.

For typed,

$$
r_{i j}=\left\{\begin{array}{l}
1.0-\frac{\left|b_{1}-a_{i j}\right|}{\max \left\{b_{1}-a_{i j}, a_{i j}-b_{2}\right\}}, \quad a_{i j}<b_{1} \\
1.0, \quad b_{1} \leq a_{i j} \leq b_{2} \\
1.0-\frac{\left|a_{i j}-b_{2}\right|}{\max \left\{b_{1}-a_{i j}, a_{i j}-b_{2}\right\}}, \quad a_{i j}>b_{2}
\end{array} \quad\left(1 \leq i \leq n, 1 \leq j \leq r, f_{k} \in F_{4}\right)\right.
$$

$\left[b_{1}, b_{2}\right]$ is the optimal region value of parameter $f_{k}$.

The decision eigenvalue matrix can be taken from the equations above.

From Figure 1, the experts get that the Power limiting region whose population are more, electro-enterprise are more, the total value of produce are more, economic loss of Power limiting are more, proportion of using electricity peak are more, the average temperature is more, the proportion of ice air condition are less, the distributed proportion of Power Limiting distribution for Peak Load Shifting are more.

Thus, these factors are all "b", except the scale of reconcilable peak enterprises and ice air condition are "a". 


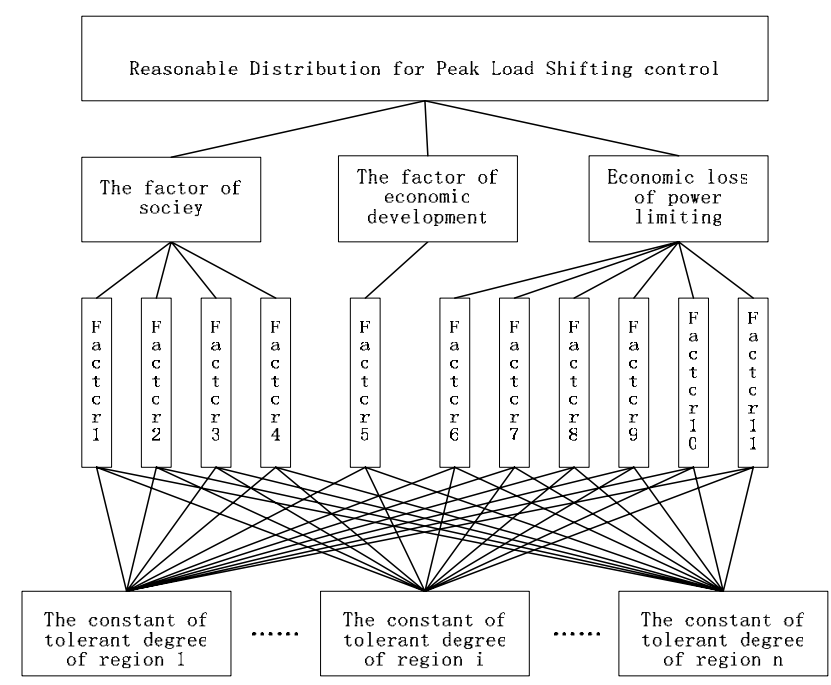

Figure 1. Decision system of Peak Load Shifting Power Limiting Distribution

factor1-The population of region

factor2- The quantity of electro-enterprise

factor3-The capacity of using power

factor4-The proportion of electro-enterprise that can be power-off

factor5-The total value of produce

factor6-The capacity of power limiting

factor7-The economic loss of power liming

factor8-The total population

factor9-The proportion of peak for using power

factor10-The average temperature

factor11-The proportion of ice air condition

\section{Parameter Relative Weight Value Calculation}

As a multi-objective decision method for combination of quality and quantity, hierarchy analysis has been applied extensively. But there are few examples about how to solve the group decision problem with hierarchy analysis method. In this paper, weighted geometry average group vector sort method based on different expert knowledge structure, has been used to deal with the hobby of some experts in multi-zone peak load shifting controlling time distribution and the problem of group hobby from knowledge structure.

\subsection{The choice of expert group}

The time of peak load shifting is mainly affected by the factors in Figure 1. Thus, the composition of expert group is always peak load shifting control expert and electric power programming expert, etc. Also including electric utility manage expert, grid economy expert and grid security expert, who are accomplished in operation, theory and scientific research respectively. Obviously, the reasonable decision weight of each expert for each factor in Figure 1 is different.

\subsection{The weight vector calculation of judging matrix for each expert}

In case of the number of expert is $\mathrm{s}$ and the number of reasonable peak load shifting control distribution factor or parameter is $\mathrm{n}$,

$$
P=\left\{P_{1}, P_{2}, \cdots P_{n}\right\}
$$

The important degree should be judged by every expert though all effecting factors. If $V$ is the important degree judged matrix for factors building by expert $i$, 


$$
V=\left(\begin{array}{ccc}
v_{11} & \ldots & v_{1 n} \\
\vdots & \ddots & \vdots \\
v_{s 1} & \cdots & v_{s n}
\end{array}\right)
$$

$V$ follows AHP method. And the weight vector of factors judged by expert $i$ can be taken according to the judged matrix.

Normalized the judged matrix $V, V^{\prime}$ can be taken.

$$
\begin{gathered}
V^{\prime}=\left(\begin{array}{ccc}
v_{11}^{\prime} & \ldots & v_{1 n}^{\prime} \\
\vdots & \ddots & \vdots \\
v_{s 1}^{\prime} & \cdots & v_{s n}
\end{array}\right) \\
v_{i j}^{\prime}=\frac{v_{i j}}{\sum_{k=1}^{n} v_{i k}}, i=1,2, \cdots \cdots, s
\end{gathered}
$$

\subsection{The synthesis of expert weight vector}

During group decision, there are two methods of composing each decision maker's weight vector: one method is to compose on the base of judgment matrix; another method is to compose on the base of weight vector. Weight vector composition mainly adopts arithmetic weighted mean composition, and that model thinks over the relative important degree between composition elements, and permeates formula in the form of weight value, which rationalizes evaluation process. Because of experts' difference in knowledge, experience, and ability, their relative importance in decision may different. Supposing $s$ experts' relative importance is all same.

Then the method of arithmetic weighted mean composition is: according to the important degree's weight vector of $n$ influencing factors arrived at separately by s experts

$$
V_{i}^{\prime}=\left(v_{i 1}^{\prime}, v_{i 2}^{\prime}, \cdots \cdots, v_{i n}^{\prime}\right)^{T} \quad i=1,2, \cdots \cdots, s
$$

Afterward, according to nether formula calculate all indicators' relative weight vector of weighted geometric mean group sorting vector $\bar{\omega}=\left(\omega_{1}, \omega_{2}, \omega_{3}, \cdots \cdots, \omega_{n}\right)^{T}$ :

$$
\begin{gathered}
\lambda_{1}=\lambda_{2}=\cdots \cdots=\lambda_{s}=1 / s \\
\theta_{j}=\sum_{k=1}^{s}\left(v_{k j}^{\prime} \times \lambda_{k}\right) \\
\omega_{j}=\theta_{j} / \sum_{i=1}^{n} \theta_{i}, j=1,2,3, \cdots \cdots, n
\end{gathered}
$$

$\lambda_{1}, \cdots \cdots \lambda_{s}$ correspond weight coefficient of decision maker ability level.

Finally, calculate standard deviation of $\omega_{j}$

$$
\sigma_{j}=\sqrt{\frac{1}{s-1} \sum_{k=1}^{s}\left(\omega_{j k}-\omega_{j}\right)^{2}}
$$

when $\sigma_{j}<\varepsilon(\varepsilon \in[0.5,1])$,we think group judgment acceptable, and feedback the indicator absolute weight vector of every decision maker to decision makers for their reference; if multiple decision makers all accept above weight vector, then calculation finishes. Otherwise, let decision maker offer amend judgment. Repeat many times in this manner, and up still all decision makers obtain satisfying weight vector.

\section{Optimized Distribution Decision Calculation of Multi-objective Power Limiting Time Distribution}

For the hierarchy model structure in Figure 1, the fuzzy synthesized decision model of multi-objective power limiting time distribution in multi-zone is established as follows.

$$
Z=R \circ W=\left(\begin{array}{ccc}
r_{11} & \cdots & r_{1 n} \\
\vdots & \ddots & \vdots \\
r_{m 1} & \cdots & r_{m n}
\end{array}\right) \circ\left(\begin{array}{c}
\omega_{1} \\
\vdots \\
\omega_{n}
\end{array}\right)
$$

In the equation above, $R$ is the relative membership degree matrix, $r_{i j}$ means the relative membership degree of the 
parameter $j$ in zone $i$ of $m, W$ is the parameter weight vector determined by group decision theory, $\omega_{j}$ is the weight of parameter $j$ of $n$ under group decision, $Z$ is the scale vector of zone power limiting time distribution. " $\circ$ " is the fuzzy arithmetic operators. The scale of power limiting distribution of each region can be taken according to equation (16).

\section{Research of Examples}

According to the data from the charge department of Liaoning province, a peak load shifting distribution in six regions is planned to operate in summer of 2005. The social economy of six regions is shown in Table I. The loss is in Table II.

If there are three decision-maker who participate in the decision of peak load shifting controlling distribution, the result can be got using the model above. (The calculation process is omit)

Table 1. The Parameter of Social Economy

\begin{tabular}{|l|l|l|l|l|l|}
\hline regions & Population(10000) & $\begin{array}{l}\text { Electricity } \\
\text { consumption } \\
\text { number }\end{array}$ & $\begin{array}{l}\text { Electricity } \\
\text { capacity(Mkw) }\end{array}$ & $\begin{array}{l}\text { Reconcilable } \\
\text { peak scale (\%) }\end{array}$ & $\begin{array}{l}\text { Product } \\
\text { gross(1000rmb) }\end{array}$ \\
\hline 1 & 56.42 & 308 & 47.28 & 17.83 & 476.52 \\
\hline 2 & 23.18 & 106 & 21.53 & 52.12 & 180.63 \\
\hline 3 & 89.13 & 416 & 62.52 & 41.63 & 725.20 \\
\hline 4 & 10.67 & 89 & 18.62 & 71.63 & 97.65 \\
\hline 5 & 36.21 & 218 & 32.15 & 31.25 & 207.26 \\
\hline 6 & 43.56 & 229 & 29.56 & 52.06 & 168.88 \\
\hline
\end{tabular}

Table 2. The Economic Loss of Power Limiting

\begin{tabular}{|c|c|c|c|c|c|c|}
\hline region & $\begin{array}{l}\text { Power limiting } \\
\text { capacity(Mkw) }\end{array}$ & $\begin{array}{l}\text { Economic loss of } \\
\text { power } \\
\text { limiting }(1000 \mathrm{rmb})\end{array}$ & $\begin{array}{l}\text { Population(myriad } \\
\text { human) }\end{array}$ & $\begin{array}{l}\text { Electricity } \\
\text { consumption } \\
\text { peak scale }(\%)\end{array}$ & $\begin{array}{l}\text { Average } \\
\text { temperature }\end{array}$ & $\begin{array}{l}\text { Ice air } \\
\text { condition } \\
\text { scale }(\%)\end{array}$ \\
\hline 1 & 41.07 & 28.71 & 50.26 & 67.12 & 32.5 & 25.6 \\
\hline 2 & 16.52 & 8.28 & 19.17 & 40.06 & 31.2 & 30.1 \\
\hline 3 & 55.73 & 34.62 & 83.54 & 62.56 & 32.7 & 25.7 \\
\hline 4 & 17.64 & 9.43 & 8.99 & 36.11 & 29.8 & 35.2 \\
\hline 5 & 27.35 & 10.52 & 34.04 & 50.12 & 30.6 & 22.6 \\
\hline 6 & 23.06 & 9.31 & 39.56 & 54.58 & 33.3 & 21.7 \\
\hline
\end{tabular}

1) Indicator absolute weight vector of decision maker 1 is $\bar{\omega}_{1}=\{0.0483,0.1690,0.0549,0.0554,0.0978,0.0052,0.1949,0.1093,0.0918,0.0602,0.1132\}$

2) Indicator absolute weight vector of decision maker 2 is $\bar{\omega}_{2}=\{0.0623,0.346,0.0650,0.0574,0.1324,0.0064,0.1529,0.0925,0.0744,0.1432,0.0789\}$

$3)$ Indicator absolute weight vector of decision maker 3 is $\bar{\omega}_{3}=\{0.0924,0.2084,0.0386,0.0621,0.1105,0.0116,0.0988,0.0863,0.1242,0.0428,0.1243\}$

4) Indicator weight vector of group decision is

$\bar{\omega}_{\text {群 }}=\frac{1}{3} \sum_{i=1}^{3} \omega_{i}$ and normalized

$=\{0.0705,0.1677,0.0557,0.0598,0.1162,0.0073,0.1404,0.0954,0.0938,0.0900,0.1032\}$ 
5) Every region's Power Limiting Distribution for Peak Load Shifting control proportions are:

$Z_{1}=7.83 \%, Z_{2}=19.75 \%, Z_{3}=4.87 \%, Z_{4}=43.52 \%, Z_{5}=12.98 \%, Z_{6}=11.05 \%$

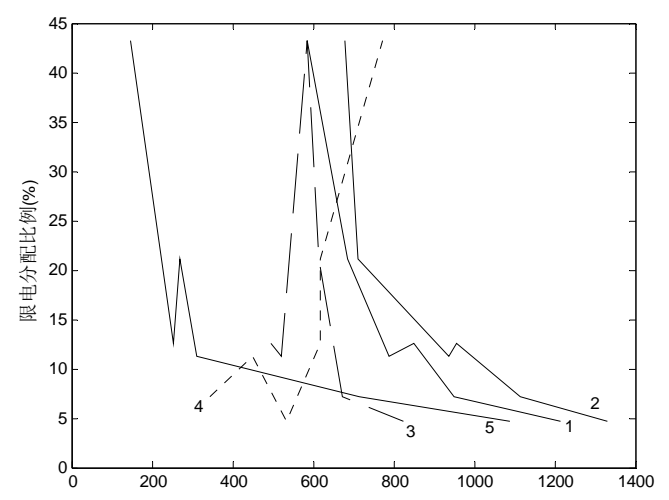

Figure 2. corresponding curve schematic diagram of social economic indicator and Power Limiting Distribution in every region

Population-1

The quantity of electro-enterprise-2

The capacity of using electricity- 3

The proportion of moving-peak enterprise-4

The total value of produce- 5

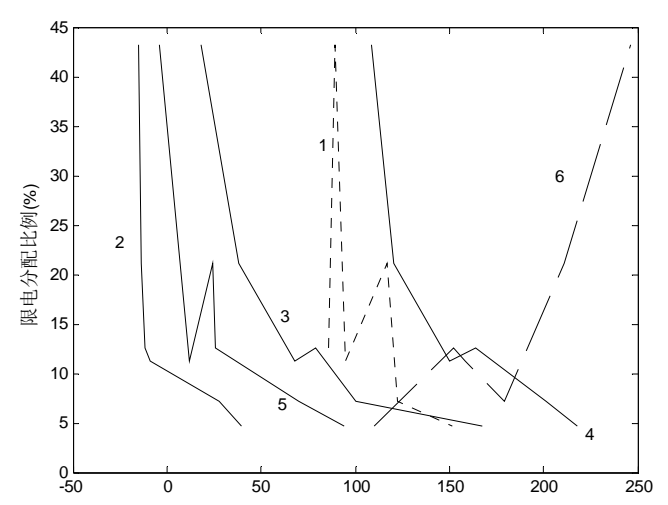

Figure 3. corresponding curve schematic diagram of the economic loss indicator of Power limiting and Power limiting Distribution proportion

Limited capacity-1

The economic loss of Power limiting-2

Population-3

Proportion of using electricity peak-4

Average temperature-5

The proportion of ice air condition- 6

\section{Conclusion}

It can be seen from the corresponding curve schematic diagram of various decision indicators and Power Limiting Distribution proportion in above region (Figure 2; Figure 3):

With the change of social economic indicators and the economic loss of power limiting in various regions, the final Power Limiting Distribution proportion also changes: the Power limiting region whose population are more, electro-enterprise are more, the total value of produce are larger, economic loss of Power limiting is larger, proportion of using electricity peak is bigger, the average temperature is higher, the proportion of ice air condition is smaller, is distributed smaller proportion of Power Limiting distribution for Peak .

In a word, power limiting distribution is a complex multi-object group decision problem, the decision of power limiting 
time distribution is not only related to technology, economy and power limiting criterion but also to the supplying safety of power grid and the stability of society, so the research of decision of power limiting time distribution is more complex. Analyzing from main factors effecting to region power limiting time distribution, criterion system of region power limiting distribution is built up in this paper, and the model and method of large-scale systematical multi-object group decision combining hierarchy analysis and fuzzy comprehensive evaluation is proposed also, and satisfied research results of actual example is obtained. But in the future it should be more strengthened on the society evaluation of power limiting distribution of peak load shifting control, economical evaluation, environmental evaluation, decision method of power limiting uncertain distribution and its reliability research.

\section{References}

Chiclana F, Herrera F \& Herrera Viedma E (1998). Integrating three representation models in fuzzy multipurpose decision making based on fuzzy preference relations. Fuzzy Sets and Systems, 9, 33-48

Delgado M, Herrera F Herrera Viedma E (1998).Combining numerical and linguistic information in group decision making. Information Sciences, 10, 177-194

H.C.Huang, R.C.Wang \& J.G. Hsieh (2002). A new artificial intelligent peak power load forecaster based on non-fixed neural networks. Electr.Power Energy Syst, 24, 245-250

Herrera F \& Herrera Viedma E (2000). Linguistic decision analysis: steps for solving decision problems under linguistic information. Fuzzy Sets and Systems, 11, 67-82

Herrera F \& Herrera Viedma E (2000). Choice functions and mechanisms for Linguistic preference relation. European Journal of Operational Research, 20, 223-239

J. Ma, Z.P. Fan \& L.H. Huang (1999). A subjective and objective integrated approach to determine attributes weights. European Journal of Operational Research, 12, 397-404

Marmol AM, Puerto J \& Fernanndez FR (1998). The use of partial information on weights in multi-attribute decision problem. Journal of Multi-attribute Decision Analysis, 7, 322-329

M. Krunic, K.I. Slavisa \& N. Rajakovic (2000). An improved neural network application for short term load forecasting in power systems. Electr. Mach. Power Syst, 28, 703-721

M.R.G. Al-Shakrchi \& M.M. Ghulaim (2000). Short term load forecasting for Baghdad electricity region. Electr. Mach. Power Syst, 28, 355-371

Noel Bryson \& Ayodele Mobolurin (1999). An action learning evaluation procedure for multiple criteria decision making problems. European Journal of Operational Research, 6, 379-386,

Shamsuddin Ahmed (2005). Seasonal models of peak electric load demand. Technological Forecasting and Social Change, 72, 609-622 